\title{
El género novelístico en la literatura ecuatoriana
}

\author{
The novelistic genre in the ecuadorian literature
}

\author{
Yovany Salazar Estrada ${ }^{1}$ \\ ysalazarec2002@yahoo.es
}

\begin{abstract}
Resumen
Se propone presentar una reseña cronológica del desarrollo evolutivo del género novelístico en la literatura ecuatoriana, desde sus orígenes hasta la actualidad. El trabajo se distribuye en seis acápites: la novela romántica y los inicios del género en la segunda mitad del siglo XIX; predominio de la ideología liberal en la fícción novelesca; realismo social e indigenismo en la novelística ecuatoriana, en las décadas del treinta y cuarenta del siglo XX; la novela de transición de la década del cincuenta; la novela ecuatoriana en las décadas del setenta, ochenta y noventa; $y$, la novelística ecuatoriana de los últimos años.
\end{abstract}

\section{Palabras claves}

Literatura ecuatoriana, narrativa ecuatoriana, novela ecuatoriana, novela histórica, novela indigenista, novela realista, novela romántica.

\begin{abstract}
It intends to present a chronological overview of the evolutionary development of the novelistic genre in Ecuadorian literature, from its origins to the present. The work is divided into six sections: romance novel and the beginnings of the genre in the second half of the nineteenth century; predominance of liberal ideology in novelistic fiction; social realism and indigenous in the Ecuadorian novel in the thirties and forties of the twentieth century; the novel of transition of the fifties; Ecuadorian novel in the seventies, eighties and nineties; and Ecuadorian novels of recent years.
\end{abstract}

\section{Keywords}

Ecuadorian literature, ecuadorian narrative, ecuadorian novel, historical novel, indigenist novel, realistic novel, romance novel.

Forma sugerida de citar: Salazar Estrada, Yovany (2015). El género novelístico en la literatura ecuatoriana. Univeristas, XIII(23), pp. 183-203.

1 Doctor en Filosofía en un mundo global (Universidad del País Vasco, 2015). Se encuentra cursando el Doctorado en Literatura Hispanoamericana en la Universidad Complutense de Madrid. Es docente de la Carrera de Lengua Castellana y Literatura de la Universidad Nacional de Loja (Ecuador). 


\section{Introducción}

El término novela procede del italiano novella, derivado, a su vez del latín nova, que significa noticia y en sus inicios fue empleado para referirse a un relato de ficción intermedio entre el cuento y la narración extensa, acepción que es utilizada por Miguel de Cervantes Saavedra (1547-1616), para titular a sus Novelas ejemplares. Solo en años posteriores el término novela: “(...) servirá para designar la narrativa extensa (...), mientras que el relato será denominado novela corta" (Estébanez, 1999, p. 746).

Asumiendo esta concepción moderna y con el propósito de presentar una ligera reseña cronológica de la novelística en el Ecuador, que contextualice cualquier estudio específico en este apasionante e inconmensurable campo de la literatura ecuatoriana, resulta pertinente apoyarse en los criterios de Ángel Felicísimo Rojas, quien en su ya clásica obra histórico crítica La novela ecuatoriana (1948) sostiene que la literatura es la traducción de un estado político y social, por lógica consecuencia, considera que para seguir el decurso de la novelística ecuatoriana: "No puede prescindirse ni de la historia política del país, singularmente accidentada, ni de su sociología rica en contenido dramático" (Rojas, 1948, p. 11).

Con estos fundamentos Rojas divide a su estudio, que va desde los inicios del género, hasta 1945, en tres épocas. La primera época: 1830-1895 de prevalencia conservadora en lo político y romántica en lo literario, con escritores que participaron de manera activa en el proyecto de constitución del Estado nacional ecuatoriano. Segunda época: 1895-1925, vinculada con la ascensión del liberalismo al poder, como producto de una de las revoluciones de mayor trascendencia de la historia republicana del Ecuador. Tercera época: 1925-1945, que corresponde al advenimiento del socialismo como doctrina y como partido político.

Con el propósito de completar el esquema de presentación de la novelística ecuatoriana formulado por Rojas se agrega la novela de transición, que incluye las pocas obras narrativas dignas de memoria que se publicaron durante la década del cincuenta del siglo anterior; luego advienen las ficciones novelescas editadas entre las décadas del sesenta, setenta y ochenta del siglo XX; y, finalmente las novelas ecuatorianas publicadas en los últimos años. 


\section{La novela romántica y los inicios del género en la literatura del Ecuador}

Corresponde a la etapa de surgimiento del género novelístico, un poco tardío, en relación al resto de países latinoamericanos, con La emancipada (1863), del militante liberal y polígrafo lojano Miguel Riofrío (1822-1879), obra que constituye un alegato en favor de la reivindicación de los derechos de la mujer que, además de describir el ambiente geográfico e histórico de su momento, anticipa algunos elementos del canon realista que tendrá su esplendor setenta años después (Salazar, 2006b: 17-21); la segunda novela es Cumandá o un drama entre salvajes (1879), hecha a imagen y semejanza de la Atala de René de Chateubriand, de autoría del católico conservador y fundador de la Academia Ecuatoriana de la Lengua Juan León Mera (1832-1894) (Salazar, 2006c: 121). Desde la orilla liberal advendrán luego: Timoleón Coloma (1888) y Relación de un veterano de la independencia (1895), de Carlos R. Tobar (1853-1920); $\mathrm{y}$, Capitulos que se olvidaron a Cervantes "ensayo de imitación de un libro inimitable" (1895), de Juan Montalvo (1832-1889), con claras influencias de la versión liberal del romanticismo francés, de Víctor Hugo y Alphonse Lamartine.

\section{Predominio de la ideología liberal en la novela ecuatoriana}

Las novelas más representativas de esta segunda etapa son: Pacho Villamar (1900), de Roberto Andrade (1850-1938), que resume el momento anticlerical furibundo del liberalismo machetero y patentiza la eufórica confianza en las bondades de este sistema de gobierno; Carlota, novela realista (1900), de Manuel de J. Calle (1866-1918), que narra la vida de una joven que emigra desde la Sierra hacia la ciudad de Guayaquil, en donde ante la imposibilidad de sobrevivir de un trabajo decente se prostituye; Luzmila (1903), de Manuel Enrique Rengel Zuquilanda (1875-1944), que se emparienta tanto con el romanticismo decimonónico, ya en decadencia, como con el realismo social de años posteriores; $A$ la costa (1904) de Luis A. Martínez (1869-1909), pionera en el tratamiento del problema emigratorio interno desde la Sierra a la Costa (Salazar, 2014, pp. 92 y ss.); Para matar el gusano (1912), de José Rafael Bustamante Cevallos (18811961), novela que, a decir de Cecilia Suárez Moreno, es el bostezo de la vertiente liberal placista que busca la conciliación con los terratenientes en el proyecto 
oligárquico (Suárez, en Carrasco, 1985); Naya o la chapetona (1912), de Manuel Belisario Moreno, una novela romántico-religiosa escenificada en la actual provincia de Zamora Chinchipe, que evoca una leyenda colonial que tuvo como protagonista a una belleza mestiza; y, Égloga trágica (1916), de Gonzalo Zaldumbide (1884-1965), una novela recordada más que nada por el cuidado estético con el que fue elaborada (Rojas, 1948, pp. 110 y ss.).

\section{Realismo social e indigenismo en la novelística ecuatoriana}

En este tercer período de nuestra historia novelística, siguiendo la tradición realista social inaugurada por $A$ la costa de Luis A. Martínez, el socialista Fernando Chávez (1902-1999) publica Plata y Bronce (1927), en la que ya esboza el esquema indigenista de novelas posteriores: un cura fanático y dominador, un teniente político sumiso a la voluntad de los señores feudales del predio contiguo y un amo blanco gamonal que explota a los indios, que viven en su latifundio y viola a sus mujeres e hijas (Salazar, 2000, p. 8). De 1927 es necesario retomar, también, Un pedagogo terrible o el vientre de una revolución, del maestro normalista Sergio Núñez (1896-1982), en la cual se pretende resumir una etapa histórica del Ecuador: la de los días que precedieron a la Revolución política del 9 de julio de 1925, destacando el papel protagónico que tuvo el profesorado normalista de Guayaquil en la preparación intelectual de ese acontecimiento (Salazar, 2000, p. 8).

Con claras influencias de las ideologías socialista y comunista y afanes de renovación literaria, en la Perla del Pacífico se estructura el llamado "Grupo de Guayaquil" o "Los cinco como un puño", de quienes, en razón de la calidad, cantidad y trascendencia de su obra novelística conviene hacer una mención individualizada, así de José de la Cuadra (1903-1941) se refiere a Los Sangurimas (1934), novela que ha sido considerada por más de un crítico, como precursora del realismo mágico latinoamericano $\mathrm{y}$, en ese sentido, parangonada con Cien años de soledad (1967), del narrador colombiano y Premio Nobel de literatura (1982), Gabriel García Márquez (1928-2014) (Salazar, 2000, p. 9).

Alfredo Pareja Diezcanseco (1908-1993) publica El muelle (1933), pionera en el tratamiento del problema emigratorio desde el Ecuador hacia Estados Unidos de Norteamérica (Salazar, 2013, pp. 73-74). Otras novelas de su autoría son La Beldaca (1935), que es la historia de una balandra de ese nombre y cu- 
yos héroes son los barqueros fluviales de la costa; Baldomera (1938), protagonizada por una zamba corpulenta y salvaje, valiente y ruda que vive en los barrios bajos de la ciudad de Guayaquil, como vendedora ambulante de alimentos populares; Hechos y hazañas de don Balón de Baba y su amigo don Inocente Cruz (1939), simboliza al idealista intelectual, cuyas esperanzas de conducir al pobre a la realización de la justicia social se ven trágicamente esfumadas; y, Las tres ratas (1944), que narra la vida de las tres hermanas: Carmelina, Eugenia y Luisa Parrales quienes, una vez que pierden la propiedad familiar heredada de su padre, abandonan el campo para dirigirse, a continuar en la lucha por la vida, en los barrios pobres de la ciudad de Guayaquil (Cfr. Salazar, 2012, p. 54-59).

Demetrio Aguilera Malta (1909-1981) publicó su primera novela Don Goyo (1933), en la que narra la vida de don Goyo Quimí, un serrano adaptado al ambiente costeño de la cholería, en el cual se ha arraigado sin perder su marca primigenia; Madrid, reportaje novelado de una retaguardia heroica (1936), una de las primeras novelas sobre la cruenta Guerra Civil Española (1936-1939); y, La isla virgen (1942), en la que nos pinta el ambiente y el alma chola y nos da a conocer la vida del mayordomo Guayamabe, original y enigmático cholo que, fatalista e impasible, muere con su patrón cuando éste en un acceso de locura, se hunde en el manglar (Salazar, 2000, p. 10).

Joaquín Gallegos Lara (1911-1947), quien publica su primera novela Las cruces sobre el agua en 1946, la cual, a decir de Agustín Cueva Dávila, constituye una bellísima historia de amor y dolor protagonizada por los habitantes de los barrios pobres de Guayaquil, que revive la masacre obrera de esa ciudad el 15 de noviembre de 1922 (Cueva, 1986). De manera póstuma y, en coautoría con Nela Martínez, aparece Los guandos (1982), que constituye una denuncia de la explotación del hombre por el hombre y de la cruel opresión a la que se ven sometidos los indios del Ecuador desde el tiempo de la colonia española. De Enrique Gil Gilbert (1912-1973) se cita Nuestro pan (1942), novela en la que se da cuenta del proceso de siembra y cosecha del arroz, cultivo de importancia en la costa ecuatoriana, porque este producto entra decisivamente en la alimentación de los pobladores de esa región y, actualmente, en los del Ecuador entero.

Simultáneamente en la Sierra emerge un robusto movimiento literario, encabezado por Jorge Icaza (1906-1978), quien en 1934, publica su primera y más famosa novela: Huasipungo, en la que expone la degradada vida de los indios de la Sierra del Ecuador, sometidos a esclavitud por los patronos, que cuentan con el apoyo de la autoridad civil y eclesiástica. En 1935, asoma En las calles, de indudable inspiración política y de denuncia y protesta social. En 1937 pu- 
blica la novela Cholos, en la que Icaza aborda el problema de la decadencia del latifundista aristocrático, descendiente de los encomenderos españoles y el ascenso de algunos mestizos a la calidad de nuevos terratenientes explotadores. En 1948 edita Huairapamushcas ("los hijos del viento" o "los hijos que trae el viento", "los hijos de nadie"), con la cual se retorna al tema indigenista de Huasipungo y se observa al patrón prepotente que engendra sin amor en la india, dando como producto otro tipo de ecuatoriano, el cholo, que desea negar y alejarse del mundo materno, para integrarse al mundo del padre que no lo reconoce (Cfr. Salazar, 2008, pp. 24-28). Por estos mismos años Gonzalo Humberto Mata (1904-1988), un quiteño avecinado en la ciudad de Cuenca, en la vertiente indigenista de Huasipungo de Jorge Icaza, publica tres novelas: Sumag Allpa (1940), Sanagüin (1942) y Sal (1963).

Aunque desde una perspectiva diferente al realismo social y al indigenismo, prevalecientes en esa época, es digna de mención la obra del narrador vanguardista lojano Pablo Palacio (1906-1947), quien en 1927 publicó Débora, en la cual, a más de iniciar la narrativa urbana en el Ecuador, defiende la importancia de tratar las pequeñas realidades frente a las grandes y voluminosas, que abordaban los cultivadores del realismo social; sin embargo, el propio Palacio en 1932 publica Vida del ahorcado, novela en la que retoma algunas dimensiones de las grandes realidades, que serán las preferidas de los autores en las dos décadas subsiguientes (Cfr. Salazar, 2006a, pp. 68-70).

Humberto Salvador (1909-1982), en la misma línea vanguardista de Pablo Palacio publica varias novelas de indudable valor: En la ciudad he perdido una novela (1929), Taza de té (1932), Camarada (1933), Trabajadores (1935), Noviembre (1939), La novela interrumpida (1942), Prometeo (1943), Universidad Central (1944), La fuente clara (1946) (Serrano, 2009). El reconocimiento y la justa valoración, en primer término le vino desde fuera de los linderos patrios, con elogiosos comentarios y apreciaciones de escritores y críticos de talla intercontinental como: Alfonso Reyes, Salvador Novo, Ramón Gómez de la Serna, Gabriela Mistral, Mariano Picón Salas, Juana de Ibarbourou, Luis Alberto Sánchez, Mario Benedetti, entre otros.

Ángel Felicísimo Rojas (1909-2003), publica Banca (1938), especie de autobiografía escolar de su experiencia estudiantil en el tricentenario Colegio Bernardo Valdivieso de Loja, El éxodo de Yangana (1949), la novela total sobre la migración interna de la Sierra a la región amazónica, en palabras de Abdón Ubidia (2006), y Curipamba (1983), en torno a la explotación aurífera, por par- 
te de una compañía transnacional de origen estadounidense, en la provincia de El Oro (Salazar, 2010a, p. 8).

Enrique Terán (1887-1941) publica El cojo Navarrete (1940), que narra la tragedia de un cholo mayordomo de la hacienda de un general alfarista que lo lleva a la guerra, en la cual pierde una pierna; luego su vida tomará un rumbo imprevisto hacia el bandolerismo. A pesar de su lenguaje algo intrincado, es una novela intensa, de acción precisa, gran aliento y personajes inolvidables, en palabras del ya citado Abdón Ubidia.

Otros autores más jóvenes, que publicaron sus primeras novelas bajo la evidente impronta de la ideología socialista, son Adalberto Ortiz (1914-2003), con Juyungo (1943), en la que recrea la vida del negro esmeraldeño y su choque contra la explotación capitalista y frente a la selva todavía virgen (Salazar, 2000 , p. 12). Con el correr del tiempo publicará otros aportes significativos a la novelística ecuatoriana: El espejo y la ventana (1967) y La envoltura del sueño (1982). Pedro Jorge Vera (1914-1999) edita Los animales puros (1946), novela intelectualizada en la que se profundiza la vida y preocupaciones de un grupo de revolucionarios que todavía no encuentran el camino seguro para arribar a la meta que se han propuesto.

La tendencia realista se evidenció en algunas novelas que se publicaron en las dos décadas siguientes. Dos ejemplos ponen en evidencia lo afirmado: Cuando los guayacanes florecían (1954) de Nelson Estupiñán Bass (19122002), obra sobre la negritud esmeraldeña que recuerda hechos históricos de las primeras décadas del siglo XX. Carente casi de descripciones, con un lenguaje austero y preciso, se sostiene, sobre todo, en las acciones de sus personajes. En la misma perspectiva está Segunda vida (1962), de Arturo Montesinos Malo (1913-2009), en la que, además, se añaden al relato social tramas intrincadas, casi policiales, muy bien resueltas (Ubidia, 2006).

\section{La novela de transición en el Ecuador}

En la historia del Ecuador, a las borrascosas décadas del veinte y treinta del siglo XX que, paradójicamente, produjeron la "edad de oro de la narrativa ecuatoriana", le sucede una etapa de relativa estabilidad económica y política, la misma que se prolonga entre 1948 y 1960; sin embargo, en estos años, se publica muy poca novela de calidad que merezca ser rememorada. Por ello, en la historia de la novela ecuatoriana, a falta de una denominación más precisa se habla de 
una "Generación de transición" y entre los novelistas más representativos de esta época se pueden mencionar los siguientes: Alfonso Cuesta y Cuesta (1912-1992), con Los hijos (1962), la cual a criterio de Jorge Dávila Vázquez evidencia: “(...) interés por el problema del mestizo; ahondamiento en las conductas y las formas de vida, las motivaciones y los sueños de unos personajes cada vez más autónomos y humanos (...); tratamiento del personaje infantil (...); paso del campo a la ciudad y a la problemática de lo urbano" (Dávila, en Cuesta, 2005, p. 24).

El ya citado Jorge Icaza publica El Chulla Romero y Flores (1958), técnica, estética, estilística y estructuralmente su obra más elaborada y lograda, con la cual se centra, definitivamente, en la problemática espiritual, en el trauma, en el conflicto del mestizo, singularizada en la figura del chulla quiteño Alfonso Romero y Flores y sus malabarismos por sobrevivir en un mundo de enajenaciones, extravíos, disfraces, impostaciones y falsas apariencias (Cfr. Salazar, 2007a, p. 131).

Alejandro Carrión Aguirre (1915-1992), con La espina (1959), cuyo leitmotiv es la soledad de un abogado mestizo y citadino, como símbolo de la soledad del hombre contemporáneo indaga en las causas de esta soledad y las ubica en la primera infancia, razón por la cual existe una amplia y detallada descripción de esta dura etapa de la vida del personaje narrador. Todo el lenguaje de la novela está atravesado por un elevado y desgarrado lirismo, el cual es coherente con la soledad, la angustia y otros sentimientos existencialistas que caracterizan al narrador protagonista, Darío Nicolás Saralear (Cfr. Salazar, 2007b, p. 3).

Juan Andrade Heyman (1945), con El lagarto en la mano (1965) transgrede las convenciones tradicionales de ordenar la narración al "minar los conceptos de secuencia cronológica y estructuración racional" (Chica, 1995, p. 4). Más tarde publicará: La erección de San Fernandito -en colaboración con Sócrates Ulloa- (1975) y Alerta roja (1995).

Rafael Díaz Ycaza (1925-2013), con sus novelas: Los rostros del miedo (1962), en la que denuncia la pobreza de los empleados públicos del Ecuador, especialmente el maestro de escuela, y Los prisioneros de la noche (1967), en la cual ahonda en estados de conciencia y subconsciencia, enriqueciendo el repertorio temático, innovando los modos narrativos, con su forma especial de montaje, cambios de sujeto en la narración, juegos contrapuntísticos y otras técnicas narrativas, comunes a lo que se viene haciendo en el resto del continente.

Alsino Ramírez Estrada (1930) se hace presente con El testimonio (1967), obra que fue calificada por Humberto Albornoz como “(...) novela de experimentación psicológica que propone al lector una fórmula de dinamismo fati- 
gante que lo lleva a ser el realizador y el pasivo receptor de ideas y circunstancias" (Citado por Oñate, 2002). Tiempo después publicará: Ceremonial (1975), Crónica de la medianoche (1983) y Las dudosas memorias (1999).

\section{La novela ecuatoriana en las décadas del setenta, ochenta y noventa}

Desde una perspectiva ideológico-política y estética bastante relacionada con el socialismo que estuvo en el trasfondo del realismo social, de las décadas del treinta y cuarenta, se hace necesario recordar que durante los años sesenta, entre el grupo de intelectuales jóvenes de tendencia renovadora se hace muy evidente la influencia del triunfo de la Revolución Cubana de 1959 y la efervescencia de los movimientos de liberación nacional, juveniles y estudiantiles, de esos años. Hechos externos y revisión de la tradición realista, antes mencionada, que derivan en la constitución del movimiento cultural contestatario Tzánzico (reductores de cabezas), la Asociación de Artistas Jóvenes del Ecuador, y el Frente Cultural, con su órgano de difusión, la revista La bufanda del sol, que asumen como emblema de lucha el "parricidio cultural", la toma simbólica de Casa de la Cultura Ecuatoriana "Benjamín Carrión" y el cuestionamiento de las dictaduras de las décadas del sesenta y setenta (Chica, 1995, p. 31). En este contexto de efervescencia política, los jóvenes escritores, nacidos en la década de los años cuarenta, ocupan la mayor parte de su tiempo y preocupaciones en la manifestación pública, la organización estudiantil al interior de las universidades estatales, la representación de obras de teatro militante y la escritura y recitación de poesía protesta.

Y como la novela es un género que requiere de mayor tiempo de dedicación y maduración, esta advendrá de manera desbordante en las dos décadas siguientes. Y en un contexto hispanoamericano y nacional de presencia permanente de los gobiernos dictatoriales, estos serán un tema recurrente de los novelistas ecuatorianos, en cuya escritura participan algunos autores ya mencionados en páginas anteriores y otros de la nueva generación.

Cinco ejemplos justifican la aseveración: Las pequeñas estaturas (1970), de Alfredo Pareja Diezcanseco, en donde frente a los aún "omnipotentes patriotas" que ofrecen salvar al país, lo que realmente se pone de manifiesto son "las pequeñas estaturas", así como: el general dictador, el experto extranjero, las credulidades y exasperaciones populares, la represión policial, los partidos tra- 
dicionales, los grupos dominantes y sus conciliábulos secretos (Salazar, 2012: 156-157); El secuestro del general (1973), de Demetrio Aguilera Malta, novela esperpéntica, sobre la dictadura y la realidad política de Hispanoamérica; $M a$ ría Joaquina en la vida y en la muerte (1976), de Jorge Dávila Vázquez (1947), en torno a la dictadura del general Ignacio de Veintimilla (1876-1883) y las relaciones incestuosas con su sobrina Marieta; El pueblo soy yo (1976), de Pedro Jorge Vera, sobre el caudillo populista José María Velasco Ibarra, quien fue elegido presidente del Ecuador en cinco períodos y dominó la escena política nacional durante cuatro décadas (1932-1972); y El destierro es redondo (1979), de Edmundo Ribadeneira (1920-2004), que alude a la prisión y destierro que sufrió el autor, por parte de la dictadura militar de 1963.

En relación directa con las novelas antes mencionadas está, también, la preocupación por la historia del Ecuador, aspecto que constituye el trasfondo de $\mathrm{La}$ Linares (1975), de Iván Egüez (1944), en la cual, a través de la creación de un personaje mítico, como dice Jimmy Jorge Chica (1995), ha concitado el interés de la crítica, además, por articular elementos experimentales de la modernidad narrativa y hacer alarde de un estilo neobarroco.

El trasfondo ideológico es otro de los aspectos comunes a las novelas ecuatorianas publicadas durante la década del setenta. Entre Marx y una mujer desnuda (1976), de Jorge Enrique Adoum (1926-2009), con un título que a más de aludir a la adhesión y compromiso con la ideología marxista, constituye una novela experimental, en donde se reflexiona sobre el acto de escribir y se entretejen magistralmente forma y contenido, lenguaje y sociedad; El desencuentro (1976), de Fernando Tinajero (1940), que presenta la crisis ideológica de la generación marxista de la década anterior; Polvo y ceniza (1979), de Eliécer Cárdenas Espinoza (1950), en la cual, desde una perspectiva socializante, se rememora la vida y hazañas del bandolero lojano Naún Briones y sus compañeros, quien cual un Robin Hood moderno robaba a los ricos para repartir entre los pobres (Cfr. Salazar, 1994, p. 140).

Existe también una vuelta al indigenismo, con Dos muertes en una vida (1971), de Alfonso Barrera Valverde (1929-2013), en donde se narra la historia de Juan Hiedra, un indígena que abandona el campo para ir a la ciudad capital en busca del trabajo que le permita seguir estudiando y muere en una protesta estudiantil. Indigenismo que, asimismo, aparece reactualizado en Porqué se fueron las garzas (1979), de Gustavo Alfredo Jácome (1912), en donde la búsqueda de la identidad del indígena ocupa un lugar destacado (Mikou, 2007, pp. 
88-89). En la línea neo-indigenista es oportuno mencionar, también, la novela Y Rojo es el poncho del chirote (1991), de Marcelo Robayo (1940).

La presencia de la mujer en la novelística ecuatoriana se hace sentir, con Alicia Yánez Cossío (1929), quien en Bruna, soroche y los tíos (1973) cuenta, a través de una mujer joven que simboliza a la mujer universal, los avatares de la cultura andina que agoniza desde hace 500 años. Tiempo después publica: Yo vendo unos ojos negros (1979), Más allá de las islas (1980), La Cofradía del Mullo del vestido de La Virgen Pipona (1985) y La Casa del sano placer (1989), en donde narra el problema social de la prostitución en la ciudad de Quito. Compleja temática que, también, será abordada por Eugenia Viteri (1932), en Alcobas negras (1984).

En una línea experimental se ubican las novelas Las tierras del Nuaymás (1975), de Jorge Rivadeneyra (1930), en la que se desarrollan interesantes experimentaciones con el lenguaje en busca de la polisemia, el exceso de significación, el sentido profundo del lenguaje y su dinámica, y en Día tras día (1976), de Miguel Donoso Pareja (1931), que plantea la necesidad de la reinvención permanente en el arte, en el lenguaje y en la propia existencia humana.

En las novelas de las décadas del ochenta y noventa se insiste en la recuperación del pasado histórico del Ecuador y los problemas sociales del presente, como preocupación de la novela, conforme lo ponen en evidencia: Háblanos Bolivar (1983), Diario de un idólatra (1991), Que te perdone el viento (1993) y El obscuro final del porvenir (2000), de Eliécer Cárdenas Espinoza (Cfr. Salazar, 1994: 140); Pájara la memoria (1985), El poder del Gran Señor (1985) y Sonata para sordos (1999), de Iván Egüez; Tambores para una canción perdida (1986), de Jorge Velasco Mackenzie (1949), y Mientras llega el día (1990), de Juan Valdano (1940).

En similar perspectiva ha trabajado Luis Zúñiga (1955), con sus novelas: Manuela (1991), que recrea la vida de Manuela Sanz, destacado personaje femenino, que luchó junto a Simón Bolívar durante el proceso de liberación de América Latina del yugo ibérico y Rayo (2000), que narra el asesinato a machetazos del presidente Gabriel García Moreno, a manos del talabartero de origen colombiano Faustino Lemos Rayo. Alfonso Reece Dousdebés (1955), con Morga (2007), aborda la extraña personalidad de Antonio Morga, quien fuera presidente de la Real Audiencia de Quito entre 1615 y 1636 y, a través de él, trata de temas de historia de la conquista y colonización americana, por parte de España, época en la que se atropelló la dignidad humana del indígena y se cometieron los más horrendos crímenes. Y Byron Rodríguez Vásconez (1960), 
con Guerra de la funeraria (2007), que: "Es una novela que abraza la ciudad de Quito, con ese espíritu burlón, chispeante, amante de las fiestas y la chismografía; pero, principalmente, es la crónica del fallido golpe de Estado de septiembre de 1975 " (Sacoto, 2008, p. 8).

La crisis ideológica vuelve a trabajarse en algunas de las novelas más representativas de este período, como: Teoría del desencanto (1985), de Raúl Pérez Torres (1941), en la cual se plasma una visión de pesadilla, interiorizada y obsesiva, de la realidad caótica del período histórico del Ecuador que le sirve de telón de fondo, destacando el fracaso de los ideales revolucionarios de la juventud quiteña de la década del sesenta (Chica, 1995, pp. 169-170). En Los diamantes y los hombres de provecho (1989), de Eliécer Cárdenas Espinoza, se refieren los encuentros de tres adolescentes: Gauguin, Alicia y Alejandro que, con el devenir del tiempo, se sienten fracasados, frustrados y traidores, por cuanto no han podido cumplir o han sido infieles a sus ideales de juventud (Cfr. Salazar, 1994, p. 141). De similar manera son novelas saturadas de ideología y sueños revolucionarios frustrados: Una buena razón para matar (1990), de Raúl Rojas Hidalgo; Azulinaciones (1990), de Natasha Salguero (1948); y, El devastado Jardín del paraíso (1990), de Alejandro Moreano Mora (1944).

Francisco Proaño Arandi (1944), el "artífice de las atmósferas cargadas y el estilo barroco y moroso pero también de la observación aguda y poética de los mundos desolados" (Ubidia, 2006, p. 314), en Antiguas caras en el espejo (1984), teje una narración acerca de los orígenes del fascismo sudamericano; en Del otro lado de las cosas (1993), dilucida un enigma, prevé el futuro y emprende la búsqueda de la identidad posible, entre las contrapuestas máscaras del poder, la inquisición en un tiempo que ha dejado de ser heroico, y en La razón y el presagio (2003), que es una novela con cierta intencionalidad política, con personajes que vienen de fuera, en la cual aparecen muchos tomados de la realidad allende el país: unos exiliados, por ejemplo, de la guerra yugoslava, que se encuentran en el Ecuador.

Una vez completado el proceso urbanizador, a partir de la década del sesenta, la ciudad se convierte en la "patria del individuo, el territorio privilegiado de sus conflictos. Soledad, incomunicación, neurosis, competencia, definen la psique del habitante de la ciudad" (Ubidia, 2006, p. 312). Por lo que se constituye en el terreno privilegiado donde nace una literatura que se rige por patrones muy distintos a los del realismo social. En este nuevo escenario, continuando una tradición de la narrativa urbana iniciada por el vanguardista lojano Pablo Palacio, en el año de 1927 y, con la reconocida influencia del boom latinoame- 
ricano, Ciudad de invierno (1984) y Sueño de lobos (1986), de Abdón Ubidia (1944) entran con fuerza a recrear la problemática de la ciudad y, en ellas, la urbe no sólo constituye el escenario geográfico de la ficción sino que asume un rol protagónico, como una de las realidades y manifestaciones más palmarias de la modernidad capitalista en el Quito de finales de la década del setenta, con todas las paradojas y contradicciones que le son inherentes (Salazar, 2006b, pp. 99-104). Respecto de la vida en un sector suburbano de la ciudad de Guayaquil, con preferencia por los personajes marginales, es digna de destacar El rincón de los justos (1983), del ya mencionado Jorge Velasco Mackenzie.

Tema que es retomado en novelas posteriores como Vientos de agosto (2003), de Carlos Arcos Cabrera (1951), en donde se emprende el enjuiciamiento de una ciudad "bastante retrógrada, atrasada y sumida en un tradicionalismo mezquino donde las gentes y sus aspiraciones son un reflejo de la idiosincrasia de dicho pueblo" (Sacoto, 2008, p. 9) y El palacio del diablo (2005), de Modesto Ponce Maldonado (1938), una novela sobre la ciudad de Quito, con toda su idiosincrasia y prejuicios. Pero, sobre todo, corroída por el llamado progreso y modernidad, que aún no puede superar los problemas de inequidad, pobreza y explotación de la mayoría de sus habitantes.

Desde la provincia de Esmeraldas se destaca la presencia de la primera novelista negra: Argentina Chiriboga (1940), con Bajo la piel de los tambores (1991), respecto de la cual Raúl Pérez Torres comenta que se trata de una "Novela que recoge también un momento convulsionado de nuestra historia, una pieza más en el rompecabezas histórico que los creadores escriben como homenaje para su pueblo" (Citado por Oñate, 2002). Su próxima novela es Jonatás y Manuela (1994), en donde se ponen en evidencia los prejuicios machistas y racistas, en contra de la mujer negra.

\section{La novela ecuatoriana de los últimos años}

La preferencia por los temas históricos sigue vigente en la novelística ecuatoriana, conforme lo demuestra la ya mencionada Alicia Yánez Cossío, quien publica nuevas novelas tomando como referente la vida de personajes destacados en la historia del Ecuador. Ejemplos de esta naturaleza son Aprendiendo a morir (1997), en torno a Santa Mariana de Jesús; Sé que vienen a matarme (2001), sobre la vida y asesinato del presidente Gabriel García Moreno; Memorias de la Pivihuarmi Cuxirimay Ocllo (2008), en la que se narra la vida de la 
hija de Huayna Cápac quien, cuando se produce el asesinato de Atahualpa por parte de Francisco Pizarro, se convierte en la esposa de Pizarro y, cuando éste muere, a consecuencia de la guerra civil entre conquistadores, Cuxirimay Ocllo se casa con Juan de Betanzos, quien deja escrito para la posteridad lo que su esposa le relata de los increíbles acontecimientos de la conquista del Perú. Finalmente en Y amarle pude... (2012), narra la corta pero intensa vida de la poeta romántica quiteña Dolores Veintimilla de Galindo, quien fue víctima de mentiras, calumnias y fuertes críticas, por parte de la sociedad conservadora y fanática de su época, que la presionó hasta provocarle el suicidio.

Vladimiro Rivas Iturralde (1944), con El legado del tigre (1997), novela que tiene como tema central la nostalgia del hijo, el rechazo del padre y la búsqueda de las raíces, de los orígenes, de la identidad; La caída y la noche (2001), en la que se presenta a Patricio, el personaje protagónico, como un profundo y desesperado buscador, como un viajero que no parece acabar de hallarse en su viaje hacia el fin de la noche. En torno a la identidad, Javier Ponce Cevallos (1948), en El insomnio de Nazario Mieles (1990) narra la historia de Almalepra, un hombre de origen indígena y estrato social marginal, que a lo largo de su vida se pasa el tiempo escondiendo su identidad, huyendo y ocultándose hasta el punto de carecer voluntariamente de nombre y de rostro. Desplazado del mundo, Almalepra sobrevive de diversas maneras, siempre de forma solitaria y brutal, alejado de todo contacto social, hasta que conoce a Nazario Mieles y Zulia Pando. Estos personajes le obligan a asumir su destino y enfrentarse a él, aunque sea mucho después de haberlos conocido, al final de su vida.

La mirada a la región oriental del Ecuador y a géneros novelísticos poco cultivados en el Ecuador se produce con Ernesto Torres Terán (1956), quien en Asedios profanos (1996), cuenta cómo en la Amazonía ecuatoriana se formó un mundo a partir de la explotación petrolera, que se inició a fines de los años setenta en Lago Agrio (Provincia de Sucumbíos) y Los elefantes no existen (2001), novela negra enclavada en el Región Amazónica del país, que desarrolla temas como el narcotráfico, el terrorismo, las misiones religiosas, el periodismo investigativo y las tribus huaoranis. Santiago Páez Gallegos (1958), en el género policíaco y la novela negra, publica obras como: La reina mora (1997), Los archivos de Hilarión (1998) y Condena madre (2000). Sobre este mismo tipo de novela se tiene que mencionar, también, al ya citado Juan Valdano, con Anillos de serpiente (1998).

En una línea temática propia de la sociedad contemporánea, caracterizada por el predominio del conocimiento, el informacionalismo y las tecnologías de 
la información y la comunicación, Raúl Vallejo Corral (1959), publica Acoso textual (1999), novela en la cual ¿una? ¿un? estudiante universitario explora su identidad inventando múltiples personalidades virtuales e intercambiando correos electrónicos con curiosos personajes, virtuales ellos también, alrededor del mundo y El alma en los labios (2003), sobre la "vida, pasión y muerte" del poeta guayaquileño Medardo Ángel Silva (Carrión, 2014, p. 165).

Dentro de la novela contemporánea, una mención especial amerita la novela que representa el fenómeno sociológico de la emigración internacional de los ecuatorianos, dentro de cuya temática destacan: El Inmigrante (2004), de Gonzalo Merino Pérez (1939); El sudaca mojado (s.f.), de Mauricio Carrión Márquez; Los hijos de Daisy (2009), de Gonzalo Ortiz Crespo (1944); Camas calientes (2005), de Jorge Becerra (1944); La memoria y los adioses (2006), de Juan Valdano Morejón (1940); Trashumantes en busca de otra vida (2012), de Stalin Alvear (1942); La seducción de los sudacas (2010), de Carlos Carrión Figueroa (1944), aún inédita; y, dos de las siete historias (novelas cortas) derivadas de esta voluminosa ficción novelesca: La utopía de Madrid (2013) y La mantis religiosa (2014) (Salazar, 2014, pp. 105-122).

$\mathrm{Y}$ junto a estas ficciones es necesario mencionar seis novelas en las que se presentan como personajes protagonistas a viajeros, y en las cuales el viaje se convierte en un fin en sí mismo: El viajero de Praga (1996), de Javier Vásconez (1946); Destino Estambul (1998), de Jaime Marchán (1947); De Loja a Roma pasando por donde Maite, peregrinación de un catecúmeno necio (2000), de Carlos Carrión Figueroa (1944); El Viaje de Padre Trinidad (2005), de Eliécer Cárdenas Espinoza (1950); y, El desterrado (2000) y Kazbek, de Leonardo Valencia (1969) (Salazar, 2014, pp. 88-92).

Para concluir esta breve reseña en torno a la novela ecuatoriana se considera pertinente retomar las palabras de Leonardo Valencia, quien sostiene que la novela como género literario, “(...) desde sus orígenes (...) es un espacio de convivencia de distintas voces (...) los buenos novelistas tratan de no juzgar a sus personajes, sino permitir distintos puntos de vista. Entonces, en ese sentido, la novela siempre es abierta. (...) la novela ecuatoriana está totalmente abierta a distintos caminos" (Valencia, 2013, p. 23). En esta perspectiva es necesario pues, tener consciencia de que en la literatura ecuatoriana existen múltiples novelistas, en pleno ejercicio escriturario, cada uno en una línea diferente, por lo que, de manera inmediata y en el presente, resulta bastante difícil formular y sostener un criterio fundamentado de clasificación o agrupación. 
En esta perspectiva, de los novelistas más jóvenes, sin que sean los únicos, cabe mencionar tres nombres: Miguel Antonio Chávez (1979), con La maniobra de Heimlich (2010), una historia que versa sobre un guayaquileño que viaja a Buenos Aires para asistir ingenuamente a un taller de creatividad publicitaria, pero una vez allí se da cuenta de que en su viaje "nada es casual", porque descubre el secreto concerniente a Guayaquil, el cuento de Jorge Luis Borges. Eduardo Varas (1979), con Los descosidos (2010), en la que presenta la peripecia de un hombre que decide abandonar el hogar porque su matrimonio no es lo que alguna vez imaginó. Sale de su casa en busca de una ciudad que le dé tranquilidad y en el trayecto conoce a una mujer que también escapa de algo, y entre ambos nace una relación que se convierte en la esperanza para él; sin embargo, hay algo que siempre lo sorprende y cambia las cosas.

Y finalmente, Mónica Ojeda Franco (1988), quien en su novela La desfiguración Silva (2014), habla sobre las fronteras del arte, los márgenes y la impostura, a través de la historia de Gianella Silva, un personaje ficticio que se desenvuelve dentro del movimiento Tzánzico de los años sesenta, el rodaje de un cortometraje y las múltiples formas en las que puede ser narrada una experiencia (Cfr. Diario El Comercio, de Quito, del 8 de mayo de 2014).

\section{Conclusión}

Con lo hasta aquí expresado se pone en evidencia que la novela ecuatoriana sigue escribiéndose en abundancia. Para demostrarlo bastaría citar el caso de la ciudad de Loja, en donde son numerosos los narradores de historias ficticias, que van legando una huella imborrable, a través del sentimiento, el pensamiento y el arte de la palabra, en beneficio de las presentes y futuras generaciones. Desde esta provincia, a los nombres ya mencionados en páginas anteriores, habrá que agregar los de José Alejo Palacio (1880), creador de dos novelas cortas: La Campana de ciudadela (1954) y El Capitán García (1954); Manuel José Aguirre Sánchez (1896-1942), narrador aún influido por el romanticismo y autor de una novela tardíamente publicada Inquietud (1992); Manuel Benjamín Carrión Mora (1897-1979), autor de tres novelas: El desencanto de Miguel García (1929), Atahualpa (1934) y Porqué Jesús no vuelve (1961); Hernán Gallardo Moscoso (1903-1991), que a más de sus estudios de antropología social escribió la novela Memorial de Chañán Curi (1970). 
De los novelistas que viven en otros lugares del país y el extranjero, algunos de los cuales aún se encuentran en plena labor creativa, son dignos de mencionarse: José Antonio Figueroa Sánchez (1908), escritor que nos legó dos novelas: Guerrillero de los Andes (1972) y La dama Fatal o El duende (1985); Nicolás Kingman Riofrío (1918), con Dioses, semidioses y astronautas (1982); Gonzalo Merino Pérez (1938), autor de varias novelas, inspiradas en múltiples temáticas: Gabriela o la ingratitud de la sangre (1966), Oro y miseria (1995), La Colegiala (2000), Rebelde agonía (2003), El inmigrante (2004), Vuelta a la razón (2011); Leonardo Maximiliano Kosta Ruiz, con dos narraciones largas: Neftali Pascuales (1996) y Cajeta de Celaya (1999); Aura Cumandá Aguirre Aguirre (1944), autora de Una mujer sin soledad (1999); Manuel Vivanco Riofrío (1953), con Los gagones de Solanda (1999); Carlos Paladines Escudero (1947), con Conjeturas sobre Erophilia la amante de la sabiduría y el amor: biografia novelada de Manuela Espejo (2001); y, Hugo González Carrión (1960), con dos novelas: Goyo y la virgen de piedra negra (2006) y La confesión (2010).

De los residentes en la ciudad de Loja, se deben mencionar: Stalin Alvear (1942), creador de novelas como: El viaje de Simón Bolivar a Loja (2002) y El reino de los vencidos (2006); Carlos Carrión Figueroa (1944), narrador profesional, que a más de las novelas ya mencionadas en páginas anteriores es autor de El deseo que lleva tu nombre (1990), Una niña adorada (1990), Una guerra con nombre de mujer (1994) y ¿Quién me ayuda a matar a mi mujer? (2005); Luis Salvador Jaramillo Idrovo, autor de El antifaz de los Bristol (2012); Manuel Alexander Velepucha Ríos (1984), con Una rosa en el desierto (2009) y La muerte de la tragedia (2013); y, Lenin Vladimir Paladines Paredes (1991), con la laureada novela: El diario de Lorenzo (2011).

La enumeración antes efectuada pone en evidencia que, en Loja, como en el resto del Ecuador, la producción novelística se mantiene irrefrenable porque, por lo que se conoce, en la ciudad de Loja, hay novelas inéditas que muy pronto saldrán a la luz, conforme lo evidencian Guardián de los sueños (2012), de Ana Paulina Soto Aymar (1973) y Rostro fantásmico (2013), de Miguel Ángel Saritama Valarezo (1984).

Finalmente es necesario puntualizar que, de la sucinta reseña cronológica sobre la novelística ecuatoriana, desde los inicios del género hasta la actualidad, se desprende que la producción creativa en este género narrativo ha sido muy proficua y muchas de las novelas ecuatorianas mencionadas tienen una calidad artística literaria y trascendencia, que las hace comparables con obras 
novelísticas más reconocidas del universo hispánico. Su futuro es, asimismo, muy promisorio; por cuanto, la producción novelística ecuatoriana, al igual que en el resto del mundo, continuará, porque a la novela se le siguen atribuyendo funciones que mantienen plena vigencia en el momento actual y en el futuro, como las de describir y denunciar, en forma velada y artística, una problemática social, económica, ideológica, política, religiosa o cultural e incluso esbozar nuevas utopías como alternativas de cambio; descubrir lo invisible, lo no dicho, lo olvidado, lo marginado, lo perseguido; despertar, advertir, inquietar, difundir ideas, distraer, disertar, concienciar y desautomatizar o desembotar nuestra inteligencia, sensibilidad y capacidades sensoperceptivas que, como seres humanos tenemos la ineludible obligación de defender, contra viento y marea, y en cuyo proceso, a través de la creación novelesca, siempre habrá pensamiento, sentimiento, imaginación, creación, recreación, arte, estética e ideología.

\section{Bibliografía}

Alvear, Stalin (2012). Trashumantes en busca de otra vida. Quito: Libresa.

Becerra, Jorge (2005). Camas calientes. Quito: Triana.

Cárdenas Espinosa, Eliécer (1986). Polvo y ceniza, Bogotá-Quito: Editoriales Oveja negra y El Conejo.

(2005). El viaje del padre Trinidad. Quito: Norma.

Carrasco Vintimilla, Adrián; Vintimilla, María Augusta; Suárez, Cecilia (1988). Estado, nación y cultura: los proyectos históricos en el Ecuador. Cuenca: Universidad de Cuenca.

Carrión, Carlos (2000). De Loja a Roma pasando por donde Maite, peregrinación de un catecúmeno necio. Loja: Mundimar Ediciones. (2010). La seducción de los sudacas. Loja: Inédito.

(2013a). La utopía de Madrid. Quito: El Conejo.

(2013b). Raúl Vallejo, El alma en los labios. Kipus, 33, 165-167. Quito: Universidad Andina Simón Bolívar.

(2014). La mantis religiosa. Quito: Libresa.

Carrión Márquez, Mauricio (s.f.). El sudaca mojado. Machala: Gobierno Provincial Autónomo de El Oro.

Chica, Jimmy Jorge (1995). La novela ecuatoriana contemporánea de 1970-1985 y su marginación. Nueva York: Peter Lang. 
Cuesta y Cuesta, Alfonso (2005). Los hijos, edición preparada con estudio introductorio, cronología y notas por Jorge Dávila Vázquez. Quito: Libresa.

Cueva Dávila, Agustín (1986). Lecturas y rupturas. Quito: Planeta.

Estébanez Calderón, Demetrio (1999). Diccionario de términos literarios. Madrid: Alianza.

Guerrero Jiménez, Galo (2006). Breves comentarios literarios. Loja: Universidad Nacional de Loja.

Jimbo Córdova, Aquiles Hernán (2013). El retorno. Quito: El Conejo.

Martínez, Luis A. (2005). A la costa, edición preparada con estudio introductorio, cronología y notas por Diego Araujo Sánchez. Quito: Libresa.

Mera, Juan León (2003). Cumandá o un drama entre salvajes. Quito: Casa de la Cultura Ecuatoriana.

Merino Pérez, Gonzalo (2004). El inmigrante. Guayaquil: Imprenta Magos.

Mikou, Mohammed (2007). La novela de la dictadura en el Ecuador de los años: la imaginación al servicio de la realidad (Tesis doctoral). Universidad Complutense de Madrid, España.

Oñate, Iván y Serrano Sánchez, Raúl (2002). Panorámica de la literatura ecuatoriana del siglo XX y comienzos del XXI. Recuperado de www.literaturaecuatoriana.com, 16 de mayo de 2014.

Ortiz Crespo, Gonzalo (2009). Los hijos de Daisy. Quito: Alfaguara.

Palacio, Pablo (2000). Obras completas, edición crítica coordinada por Wilfrido Corral, Madrid: ALLCA XX, Colección Archivos, Volumen 41.

Pareja Diezcanseco, Alfredo (2003). El muelle. Quito: Libresa.

Riofrío, Miguel (2003). La emancipada. Quito: Casa de la Cultura Ecuatoriana.

Rodríguez, Martha (2006). Narradores ecuatorianos de la década de 1950: poéticas para la lectura de modernidades periféricas (Tesis de Maestría). Universidad Andina Simón Bolívar, Quito, Ecuador.

Rojas, Ángel Felicísimo (1948). La novela ecuatoriana. México, D.F.: Fondo de Cultura Económica.

(1985). El éxodo de Yangana. Quito: El Conejo.

Sacoto, Antonio (1990). 14 novelas claves de la literatura ecuatoriana. Cuenca: Universidad Estatal de Cuenca.

(1990). 20 años de novela ecuatoriana. Cuenca: Universidad Estatal de Cuenca. (2008). La actual novela ecuatoriana y otros ensayos. Quito: Casa de la Cultura Ecuatoriana "Benjamín Carrión".

Salazar Estrada, Yovany (1994). La perspectiva narrativa en la novela Polvo y ceniza de Eliécer Cárdenas Espinoza. Revista del Colegio Experimental Bernardo 
Valdivieso, Tercera Época, 2, 137-157. Loja: Talleres Gráficos del Colegio Experimental Bernardo Valdivieso.

(2000). Lectura plural de la Mala hora de Leopoldo Benites Vinueza. Loja: Casa de la Cultura Ecuatoriana "Benjamín Carrión".

(2006a). Pablo Palacio: heraldo de la moderna narrativa ecuatoriana (1906-

1947). Quito: Crear.

(2006b). Micro ensayos de crítica literaria. Loja: Casa de la Cultura Ecuatoriana

"Benjamín Carrión".

(2006c). Religión católica y ficción narrativa en las novelas La emancipada de

Miguel Riofrío y Cumandá de Juan León Mera. Mediodía Revista de litera-

tura y arte de la Casa de la Cultura Ecuatoriana "Benjamín Carrión”, 54,

12-127.....Loja. Núcleo Provincial de Loja,

(2007a). El conflicto del mestizo en El Chulla Romero y Flores de Jorge Icaza.

Revista cientifico literaria del Colegio Bernardo Valdivieso, Tercera Época,

9, 126-142.

(2007b). "El conflicto padre / hijo en La espina de Alejandro Carrión". Loja: Inédito.

(2008). Estudio introductorio. En J. Icaza, Huairapamushcas (pp. 9-70). Quito: Libresa.

(2010a). Pensamiento liberal y socialista en la obra de Ángel Felicísimo Rojas,

Loja: Casa de la Cultura Ecuatoriana "Benjamín Carrión".

(2010b). La ideología socialista en Banca de Ángel Felicísimo Rojas. Mediodía

Revista de literatura y arte de la Casa de la Cultura Ecuatoriana "Benjamín

Carrión”, 57, 64-72. Núcleo Provincial de Loja.

(2012). La hoguera bárbara ¿Novela histórica o biografía novelada? Mediodía

Revista de literatura y arte de la Casa de la Cultura Ecuatoriana "Benjamín Carrión”, 59, 49-68. Núcleo Provincial de Loja.

(2013). La migración en la novelística lojana. Loja: Casa de la Cultura Ecuatoriana "Benjamín Carrión".

(2013). Trashumantes en busca de otra vida, de Stalin Alvear, y la migración internacional. Mediodía Revista de literatura y arte de la Casa de la Cultura Ecuatoriana “Benjamín Carrión”, 57, 15-36. Núcleo Provincial de Loja.

(2014). La emigración internacional en la novelística ecuatoriana (Tesis doctoral). Universidad del País Vasco, San Sebastián, España.

Serrano Sánchez, Raúl (2009). En la ciudad se ha perdido un novelista: la narrativa de vanguardia de Humberto Salvador. Quito: Ministerio de Educación / Universidad Andina Simón Bolívar, Sede Ecuador. 
Ubidia, Abdón (1999). Ciudad de invierno y otros relatos. Quito: Eskeletra. (2006). Un siglo del relato ecuatoriano. En: Fabián Corral Burbano de Lara, Testigo del siglo: el Ecuador visto a través de diario El Comercio, 1906-2006 (pp. 309-328). Quito: El Comercio.

Valdano Morejón, Juan (2006). La memoria y los adioses. Quito: Norma.

Valencia, Leonardo (2000). El desterrado. Barcelona: Debate. (2009). Kazbek. Buenos Aires: Eterna cadencia. (6 de abril de 2013). Sobre la novela ecuatoriana. El Telégrafo, p.23. Guayaquil. Vásconez, Javier (1996). El viajero de Praga. México: Alfaguara.

Vera, Pedro Jorge (1978). La semilla estéril. Quito: Casa de la Cultura Ecuatoriana "Benjamín Carrión".

Fecha de recepción: 20/10/2015; fecha de aprobación: 6/11/2015 